\title{
PEMIKIRAN AL GHAZALI TENTANG KONSEP UANG
}

\author{
Satriak Guntoro1, Husni Thamrin² \\ *1\&2 Prodi Ekonomi Syariah Program Pasca Sarjana \\ Universitas Islam Negeri Sultan Syarif Kasim Riau \\ Email: 22190313542@students.uin-suska.ac.id
}

\begin{abstract}
Abstrak: Al-Ghazali merupakan salah satu pemikir besar dalam ekonomi Islam. Lewat karya monumental Ihya Ulumuddin, al-Mustashfa Mizan, al-Amal dan At-Tibr al-Masbuk fi al-Nasihah alMulk. Al-Ghazali mengupas secara tuntas aspek-aspek subtansial dari ekonomi Islam. Karena menurutnya perkembangan ekonomi sebagai bagian dari tugas-tugas kewajiban sosial yang sudah ditetapkan Allah. Pokok permasalahan pada penelitian ini adalah bagaimana pemikiran Al-Ghazali tentang konsep uang. Penelitian ini bertujuan untuk mengetahui pemikiran Imam Abu Hamid al-Ghazali tentang konsep uang. Metode analisis yang digunakan adalah Penelitian Kepustakaan (Library Research). Dan yang dijadikan sebagai data primer dalam penelitian ini yakni data yang di peroleh langsung dari sumber utama yaitu literatur-literatur yang membahas tentang Al-Ghazali khususnya karya-karya dan pemikirannya. Hasil dari penelitian ini menunjukkan bahwa pemikiran Al-Ghazali tentang konsep uang dilatarbelakangi oleh banyaknya permasalah-permasalahan ekonomi yang terjadi dalam sistem barter atau tukar menukar barang. Al-Ghazali telah menjelaskan beberapa fungsi yang dimiliki uang, diantaranya ialah sebagai qiwam al-dunya (satuan hitung), hakim mutawasith (pengukur nilai barang), dan al-mu'awwidlah (alat tukar/medium of exchange). Dengan fungsi-fungsi tersebut uang merupakan solusi untuk mengatasi masalah perekonomian dengan sistem barter.
\end{abstract}

Kata Kunci: Al Ghazali, Ekonomi, Uang 


\section{PENDAHULUAN}

Uang merupakan sesuatu yang sangat berharga. Dalam kehidupan ekonomi, uang mempunyai peranan yang sangat penting diantaranya, uang merupakan standar nilai atas kegiatan ekonomi yang ada, baik konsumsi, produksi, atau refleksi atas kekayaan dan penghasilan (Mujahidin, 2014:57).

Imam Al-Ghazali sebagai tokoh pemikir Islam sangat memikirkan tentang permasalahan ekonomi khususnya yang berkaitan dengan uang. Hal tersebut dapat kita temui pada karya-karya Imam Al-Ghazali seperti Usul al Fiqh, alMusthafa, Mizan al-Amal dan al-Tibr al Masbuk fi Nasihat al-Mulk. Didalam karyakaryanya tersebut banyak dibahas tentang ekonomi secara luas, diantaranya, konsep evolusi pasar, aktivitas produksi, evolusi uang, peranan negara dan keuangan publik.

Imam Al-Ghazali memandang banyaknya permasalah-permasalahan dalam sistem ekonomi saat itu, salah satunya adalah permasalahan pada sistem barter atau tukar menukar barang. Menurutnya sistem barter sudah tidak sesuai lagi untuk konteks masanya. Oleh karena itu sistem ini harus dicari penyelesaiannya. Dari sinilah timbul pertanyaan-pertanyaan Al-Ghazali, yaitu; apakah dengan cara pembuatan mata uang?, dari bahan apa uang dibuat supaya bertahan lebih lama?, serta siapakah yang akan membuat uang tersebut? (Aziz, 2011:59). Pertanyaan- pertanyaan tersebut dikemukakan Al-Ghazali sebagai langkah awal untuk mencoba menyelesaikan permasalahan sistem barter.

Berdasarkan permasalahan yang telah penulis uraikan di atas maka penulis akan membahas tentang pemikiran Imam Al-Ghazali tentang evolusi uang. Sehubungan dengan itu maka penulis mengambil judul "Pemikiran Al-Ghazali Tentang Evolusi Uang”.

\section{TINJAUAN PUSTAKA Definisi Uang}

Uang secara umum adalah sesuatu yang dapat diterima secara umum sebagai alat pembayaran suatu wilayah tertentu atau sebagai alat pembayaran utang, atau sebagai alat untuk melakukan pembelian barang dan jasa (Mujahiddin, 2014:59). Menurut Al-Ghazali uang adalah alat-alat untuk mencapai suatu maksud, yakni sebagai suatu alat perantara saja tidak untuk yang lain (Aziz, 2011:54).

\section{METODE PENELITIAN}

Metode pada penelitian ini menggunakan Penelitian Kepustakaan (Library Research). Dan yang di jadikan sebagai data primer dalam penelitian ini yakni karya Al Ghazali kitab Ihya Ulumuddin dan sumber-umber lain yang berkaitan dengan pembahasan ini, baik itu berupa buku-buku atau jurnal-jurnal. Penelitian ini merupakan jenis penelitian deskriptif.

\section{PEMBAHASAN \\ Biografi Imam al Ghazali}

Imam Al-Ghazali bernama Muhammad bin Muhammad bin Muhammad bin Ahmad. Al-Imam Abu Hamid Al-Ghazali Hujjahtul Islam dilahirkan di Thusia, satu kota di Khurasan pada tahun $450 \mathrm{H}$ (1058 M) (AlGhazali : 24). Ayah beliau adalah seorang yang faqir, bekerja sebagai pemintal (ghazl) bulu domba dan menjualnya di toko di pasar. Al-Ghazali juga dikenal dengan Abu Hamid, panggilan laqob atau gelar al-Ghazali zain ad Diin ath Thusy.

Imam Al-Ghazali memulai pendidikannya di Kota Thus (456-470 H) belajar fiqh, tata bahasa (nahwu dan sharaf) kepada al-Radzakany. Ketika usia 
Al-Ghazali belum mencapai 20 tahun beliau melanjutkan studinya ke Jurjan. Disana ia belajar dengan seorang guru yang bernama Imam Al-Ismaili. Setelah itu Al-Ghazali kembali ke Thus, dan selama tiga tahun ditempat kelahirannya beliau belajar dasar-dasar Tasawuf kepada Syekh Yusuf al-Nassaj (Aziz, 2011: 24). Dan kemudian pindah ke Naisabur pada tahun $470 \mathrm{H}$, bertemu dengan Imam al Juwaini yang masyhur dengan sebutan imam alharamain, berguru kepadanya hingga wafatnya sang guru.

Beliau belajar fiqih dan ikhtilaf madzhab-madzhab, mempelajari ilmu debat dan mantiq (logika) sebagaimana para filosof, sehingga menjadi orang terbaik dalam semua itu. Karena keahliannya di bidang ilmu, termasuk filsafat, ia tidak saja terkenal di dunia Islam tapi juga di dunia intelektual barat dengan nama Algazel.

Imam Ghazali merupakan ilmuwan sekaligus penulis yang sangat produktif. Berbagai tulisan telah menarik perhatian dunia, baik dari kalangan Muslim maupun non-Muslim. Para pemikir barat abad pertengahan, seperti Raymond Martin, Thomas Aquinas dan Pascal diisukan banyak dipengaruhi oleh pemikiran Imam Ghazali. Banyak karya Imam Ghazali yang diterjemah ke dalam berbagai bahasa, seperti Latin, Spanyol, Yahudi, Perancis, Jerman dan Inggris serta dijadikan referensi oleh kurang lebih 44 pemikir Barat. Imam Ghazali diperkirakan telah menghasilkan 300 buah karya tulis yang meliputi berbagai ilmu seperti logika, moral, tafsir, fiqih, ilmu-ilmu Qur'an, tasawuf, politik, administrasi dan perilaku ekonomi. Namun yang kita kenal sampai sekarang sekitar 84 buah, diantaranya yang tidak asing lagi bagi kita adalah Ihya' ulum al-Din (Sutopo, 2013:51).

$$
\text { Al-Ghazali meninggalkan Bagdad }
$$
menuju Kota Damaskus. Al-Ghazali mengunjungi kota kelahirannya yaitu Thus, di sini pun ia berkhalwat. Keadaan skeptis Al-Ghazali berlangsung selama 10 tahun, dan pada periode itulah ia menulis karyanya yang terbesar Ihya Ulum al-Din. Selanjutnya karena desakan dari penguasan Saljuk, Al-Ghazali mengajar kembali pada Madrasah Nizhamiyah di Naisabur, tetapi hanya berlangsung selama 2 tahun, kemudian dia kembali ke Thus untuk mendirikan madrasah bagi para fuqaha, dan sebuah zawiyahi atau khanaqah untuk para mutasawwifin, dan di kota kelahirannya ini pun ia wafat pada tahun $505 \mathrm{H} / 1111 \mathrm{M}$ dalam usia 54 tahun (Sirajuddin, 2016:49).

\section{Problema Barter dan Kebutuhan Terhadap Uang}

Al-Ghazali mempunyai wawasan terhadap berbagai problema barter yang dalam istilah modern disebut sebagai:

1. Kurang memiliki angka penyebut yang sama lack of common denominator),

2. Barang tidak dapat dibagi-bagi (Indivisbility of goods),

3. Keharusan adanya dua keinginan yang sama (double coincidence of wants)

Pertukaran barter menjadi tidak efisien karena adanya perbedaan karakteristik barang-barang. Al-Ghazali menegaskan bahwa evolusi uang terjadi hanya karena kesepakatan dan kebiasaan (konvensi) yakni tidak akan ada masyarakat tanpa pertukaran barang dan tidak ada pertukaran yang efektif tanpa ekuivalensi, dan ekuivalensi demikian hanya dapat ditentukan dengan tepat bila ada ukuran yang sama.

Perdagangan dengan cara barter banyak menimbulkan masalah, bahkan akan mengurangi kelancaran jalannya perdagangan itu sendiri. Kesulitan- 
kesulitan yang dialami oleh barter ini akibat dari:

1. Proses tukar menukar akan menjadi sangat rumit karena pertkaran hanya mungkin terjadi apabila kedua belah pihak yang akan mengadakan pertukaran memilih barang yang diinginkan pihak lain dan menginginkan barang yang dimiliki pihak lain, keadaan yang demikian dinamakan kesesuaian ganda dari pada keinginan,

2. Tanpa uang akan timbul kesulitan untuk memberikan nilai ke atas sesuatu benda. Ia harus ditentukan nilainya dalan bentuk nilai tukar dengan berbagai jenis barang lain.

3. Perdagangan secara barter akan menghambat kelancaran kegiatan bisnis yang pembayarannya ditunda hingga ke masa yang akan datang.

Menurut teori Al-Ghazali, barter memang diakui telah mengisi dalam sejarah perekonmian dunia. Oleh karena itu, untuk lebih meyakinkan bahwa barter sudah perlu untuk direvisi, Al-Ghazali kemudian menganjurkan agar ada lembaga yang mengurus tentang pembuatan dan pencetakan uang. Lembaga keuangan sekaligus sebagai pencetak uang dikenal dengan sebutan Dar al-Darb (Aziz, 2011:60).

\section{Pengertian dan Fungsi Uang Menurut Al-Ghazali \\ Pengertian Uang Menurut Al-Ghazali}

Banyak para ahli yang telah mendefinisikan uang, baik itu para pemikir ekonomi dahulu maupun para ahli ekonomi kontemporer. Uang secara umum adalah sesuatu yang dapat diterima secara umum sebagai alat pembayaran suatu wilayah tertentu atau sebagai alat pembayaran utang, atau sebagai alat untuk melakukan pembelian barang dan jasa (Aziz, 2011:59).

Pemikiran Imam Al-Ghazali tentang uang dimulai dari evolusi uang hingga konsep uang. Tanpa adanya uang masyarakat akan terkendala ataupun kesulitan dalam melakukan sistem jual beli (Harahap, 2019:7). Pada dasarnya AlGhazali tidak menjelaskan tentang pengertian uang secara utuh, tetapi kita dapat mengutip pernyataannya yang menyatakan bahwa uang adalah nikmat Allah yang digunakan masyarakat sebagai mediasi atau alat untuk mendapatkan bermacam-macam kebutuhan hidupnya, yang secara substansial tidak memiliki nilai apa-apa, tetapi sangat dibutuhkan manusia dalam upaya memenuhi berbagai macam kebutuhan hidupnya (AlGhazali :96).

Menurut Al-Ghazali adalah barang atau benda yang berfungsi sebagai sarana untuk mendapatkan barang lain. Benda tersebut dianggap tidak mempunyai nilai sebagai barang (nilai intrinsik). Oleh karenanya, ia mengibaratkan uang sebagai cermin yang tidak mempunyai warna sendiri tapi mampu merefleksikan semua jenis warna. Inilah yang kemudian menjadi konsep dasar keuangan AlGhazalî, dari pernyataan di atas dapat diambil suatu definisi uang menurut AlGhazali yaitu:

a. Barang atau benda yang berfungsi sebagai sarana mendapatkan barang lain. Dengan kata lain uang adalah barang yang disepakati fungsinya sebagai media pertukaran (medium of exchange),

b. Benda tersebut tidak memiliki nilai sebagai barang (nilai intrinsik),

c. Nilai benda yang berfungsi sebagai uang ditentukan terkait dengan funsinya sebagai alat tukar. Dengan kata lain yang lebih 
berperan dalam benda yang berfungsi sebagai uang adalah nilai tukar dan nilai nominalnya (Dimiyati, 2008:59).

\section{Fungsi Uang Menurut Al-Ghazali}

Dalam kehidupan ekonomi uang mempunyai peranan yang cukup penting diantaranya, uang merupakan standar nilai atas kegiatan ekonomi yang ada, baik konsumsi, produksi atau refleksi atas kekayaan dan penghasilan (Mujahidin, 2014:57). Al-Ghazali telah menjelaskan beberapa fungsi yang dimiliki uang, diantaranya ialah sebagai qiwam al-dunya (satuan hitung), hakim mutawasith (pengukur nilai barang), dan almu'awwidlah (alat tukar/medium of exchange) (Al-Ghazali, 88-91).

Fungsi uang sebagai qiwam aldunya memiliki arti bahwa uang merupakan alat yang dapat digunakan untuk menilai barang sekaligus membandingkannya dengan barang lain, sebagaimana ilustrasi beliau yang menganalogikan uang dengan cermin. Hakim mutawasith, artinya adalah uang dapat dijadikan sebagai standar yang jelas dalam menentukan barang yang berbeda.

Sedang-kan makna uang sebagai al-mu'awwidlah menyatakan bahwa uang merupakan sarana pertukaran barang dan sebuah transaksi atau sering disebut dengan medium of exchange (Al-Ghazali: 88-91).

\section{Evolusi Uang Al-Ghazali}

Salah satu penemuan terpenting dalam perekonomian adalah uang. AlGhazali menjelaskan bagaimana uang mengatasi permasalahan yang timbul dari suatu pertukaran (barter), akibat negatif dari pemalsuan dan penurunan nilai mata uang.

\section{Problematika Barter dan Kebutuhan Terhadap Uang}

Al-Ghazali mempunyai wawasan terhadap mengenai berbagai problematika barter yang dalam istilah modern disebut sebagai:

a. Kurang memiliki angka penyebut yang sama lack of common denominator),

b. Barang tidak dapat dibagi-bagi (Indivisbility of goods),

c. Keharusan adanya dua keinginan yang sama (double coincidence of wants).

Pertukaran barter menjadi tidak efisien karena adanya perbedaan karakteristik barang-barang. Al-Ghazali menegaskan bahwa evolusi uang terjadi hanya karena kesepakatan dan kebiasaan (konvensi) yakni tidak akan ada masyarakat tanpa pertukaran barang dan tidak ada pertukaran yang efektif tanpa ekuivalensi, dan ekuivalensi demikian hanya dapat ditentukan dengan tepat bila ada ukuran yang sama.

\section{Uang yang Tidak Bermanfaat dan Penimbunan Bertentangan dengan Hukum Ilahi}

Uang tidak diinginkan karena uang itu sendiri baru akan memiliki nilai jika digunakan dalam pertukaran. Al-Ghazali menyatakan bahwa salah satu tujuan emas dan perak adalah untuk dipergunakan sebagai uang. Beliau juga mengutuk mereka yang menimbun keping-kepingan uang.

Merujuk kepada Al-Qur'an, AlGhazali berpendapat bahwa orang yang menimbun uang adalah seorang penjahat, karena menimbun uang berarti menarik uang secara sementara dari peredaran. Dalam teori moneter modern, penimbuanan uang berarti memperlambat perputaran uang. Hal ini berarti memperkecil terjadinya transaksi, 
sehingga perekonomian menjadi lesu (Jalaludain, 2014:177).

\section{Pemalsuan dan Penurunan Nilai Uang}

Uang dapat diproduksi secara pribadi hanya dengan membawa emas dan perak yang sudah ditambang ke percetakan. Standar uang komoditas, dulunya muatan logam suatu koin sama nilainya dengan nilai koin tersebut sebagai uang. Jika ditemukan emas dan perak lebih banyak, persediaan uang akan naik. Harga juga akan naik, dan nilai uang akan turun.

Perhatiannya ditujukan pada problem yang muncul akibat pemalsuan dan penurunan nilai, karena mencampur logam kelas rendah dengan koin emas atau perak, atau mengikis muatan logamnya. Pemalsuan uang bukan hanya dosa perorangan tetapi berpotensi merugikan masyarakat secara umum. Penurunan nilai uang karena kecurangan pelakunya harus dihukum (Muafi, 2016:87). Namun, bila pencampuran logam dalam koin merupakan tindakan resmi negara dan diketahui oleh semua penggunanya, hal ini dapat diterima. Beliau membolehkan kemungkinan uang representatif (token money) yang disebut sebagai teori uang feodalistik yang menyatakan bahwa hak bendahara publik untuk mengubah muatan logam dalam mata uang merupakan monopoli penguasa foedal.

Al-Ghazali juga menyatakan bahwa mencetak atau mengedarkan uang palsu lebih berbahaya dari pada menimbun seribu dirham, karena mencuri merupakan salah satu perbuatan dosa, sedangkan mencetak dan mengedarkan uang palsu dosanya akan terus berulang setiap kali uang palsu itu digunakan dan merugikan siapapun yang menerimanya dalam jangka waktu yang lebih panjang (Jalaludain, 2014:177).

\section{Larangan Riba}

Riba merupakan praktik
penyalahgunaan fungsi uang yang berbahaya, sebagaimana penimbunan barang untuk kepentingan individual. Seperti halnya para ilmuan Muslim dan Eropa, pada umumnya mengasumsikan bahwa nilai suatu barang tidak terkait dengan berjalannya waktu. Terdapat dua cara bunga dapat muncul dalam bentuk yang tersembunyi. Bunga dapat muncul jika ada pertukaran emas dengan emas, tepung dengan tepung, dan sebagainya, dengan jumlah yang berbeda atau dengan waktu penyerahan yang berbeda. Jika waktu penyerahan tidak segera dan ada permintaan untuk melebihkan jumlah komoditi, kelebihan ini disebut riba alnasiah. Jika jumlah komoditas yang diperlukan tidak sama, kelebihan yang diberikan dalam pertukaran tersebut disebut riba al-fadl. Menurut Ghazali kedua bentuk transaksi tersebut hukumnya haram.

Jika pertukaran melibatkan komoditas dengan jenis yang sama, seperti logam (emas dan perak) atau bahan makanan (gandum), hanya riba nasiah yang dilarang, sementara riba fadl diperbolehkan. Bila pertukarannya antara komoditas dengan jenis yang berbeda (logam dan makanan) keduanya diperbolehkan.

\section{SIMPULAN}

Munculnya pemikiran Imam Al-
Ghazali tentang konsep uang
dilatarbelakangi oleh banyaknya
permasalah-permasalahan ekonomi yang
terjadi dalam sistem barter atau tukar
menukar barang. Al-Ghazali telah
menjelaskan beberapa fungsi yang
dimiliki uang, diantaranya ialah sebagai
qiwam al-dunya (satuan hitung), hakim
mutawasith (pengukur nilai barang), dan
al-mu'awwidlah (alat tukar/medium of


exchange. Dengan fungsi-fungsi tersebut uang merupakan solusi untuk mengatasi masalah perekonomian dengan sistem barter.

\section{DAFTAR RUJUKAN}

Al-Ghazali. Ihya Ulum al-Din. Bairut: Dar al-Nadwah.

Aziz, Abdul. (2011). Ekonomi Sufistik Model Al- Ghazali. Bandung: Alfabeta.

Dimiyati, Ahmad. (2008). Teori Keuangan Islam Rekontruksi Metodologis Terhadap Teori Keuangan alGhazali. Yogyakarta: UII Press.

Faizal, M. F. (2015). Studi Pemikiran Imam Al-Ghazali Tentang Ekonomi Islam. Islamic Banking: Jurnal Pemikiran dan Pengembangan Perbankan Syariah, 1(1), 49-58.

Harahap, S. A. (2019). Pemikiran Imam Al-Ghaszali Tentang Fungsi Uang. Laa Maisyir: Jurnal Ekonomi Islam, 6(1), 1-15.

Jalaluddin, J. (2014). Konsep Uang Menurut Al-Ghazalî. Asy-Syari'ah, 16(2), 169178.

Thohir, M. M. B. (2016). Pemikiran Imam Al-Ghazali Tentang Ekonomi Islam dalam Kitab Ihya'Ulumuddin. IQTISHODUNA: Jurnal Ekonomi Islam, 5(2), 76-93.

Mujahidin, Ahmad. (2014). Ekonomi Islam. Jakarta: RajaGrafindo Persada

Sirajuddin, S. (2016). Konsep Pemikiran Ekonomi Al-Ghazali. Laa Maisyir: Jurnal Ekonomi Islam, 3(1).

Sutopo, S. (2013). Pemikiran Imam Ghazali Tentang Ekonomi. Ummul Qura, 3(2), 49-58. 